Article

\title{
Gas Chromatography-Mass Spectrometry-Based Metabolomic Analysis of Wagyu and Holstein Beef
}

\author{
Tomoya Yamada *, Mituru Kamiya $\$ and Mikito Higuchi \\ Division of Livestock Feeding and Management, National Agriculture and Food Research Organization, \\ Nasushiobara, Tochigi 329-2793, Japan; m_kamiya@affrc.go.jp (M.K.); mikito@affrc.go.jp (M.H.) \\ * Correspondence: toyamada@affrc.go.jp; Tel.: +81-287-37-7811
}

Received: 6 February 2020; Accepted: 5 March 2020; Published: 6 March 2020

\begin{abstract}
Japanese Black cattle (Wagyu) beef is characterized by high intramuscular fat content and has a characteristic sweet taste. However, the chemical components for characterizing the sweet taste of Wagyu beef have been unclear. In this experiment, we conducted a metabolomic analysis of the longissimus muscle (sirloin) in Wagyu and Holstein cattle to determine the key components associated with beef taste using gas chromatography-mass spectrometry (GC-MS). Holstein sirloin beef was characterized by the abundance of components such as glutamine, ribose-5-phosphate, uric acid, inosine monophosphate, 5-oxoproline, and glycine. In contrast, Wagyu sirloin beef was characterized by the abundance of sugar components (maltose and xylitol). Dietary fat is known to increase the intensity of sweet taste. These results suggest that the sweet taste of Wagyu beef is due to the synergetic effects of higher sugar components and intramuscular fat.
\end{abstract}

Keywords: metabolome; beef; Wagyu; Holstein

\section{Introduction}

Food quality, especially the taste of food, is affected by numerous chemical components. Metabolomic analysis has been used to select biomarkers from numerous metabolites. Therefore, the relationship between metabolomic profiling and food quality has been investigated to identify quality-related components. Previous reports showed that the metabolomic profiles of foods such as fermented alcoholic beverages [1], soybeans [2], and tomatoes [3], strongly affect their taste.

Metabolomic analyses of meat have also been conducted to identify quality-related components. The relationships between metabolomic profiles and processing conditions of hams [4], the muscle type of pork [5], and the sensory perceptions of pork [6] have been reported. In addition, metabolome studies of beef have shown that metabolomic profiles were affected by geographical origin [7], breed $[8,9]$, storage conditions [10], and aging periods [11].

Japanese Black cattle, also called Wagyu, are characterized by their great capacity for intramuscular adipose tissue accumulation [12,13]. The high intramuscular adipose tissue content of beef, called marbling, improves the texture, juiciness, and tenderness of Wagyu beef [13]. In sensory tests, Wagyu beef had significantly higher sensory characteristic scores than beef from other cattle breeds [14,15]. Interestingly, Wagyu beef has a characteristic sweet aroma and sweet taste that are not detected in other cattle breeds in sensory tests [15-17]. Previous reports indicated that the sweet aroma of Wagyu beef was affected by the lactone and decenal components $[18,19]$. However, the metabolomic biomarkers discerning the breed differences in beef, especially the characteristic sweet taste of Wagyu beef, have remained unclear. Holstein cattle are categorized as a dairy breed, and Holstein beef is characterized as lean meat $[20,21]$. Previous sensory test results have indicated breed differences between sensory characteristic scores of Wagyu and Holstein beef [14,15]. Therefore, to elucidate the breed differences in beef taste, a comparison of Wagyu and Holstein is thought to be the optimal model. In the present 
study, we conducted a metabolomic analysis of longissimus muscle (sirloin) samples from Wagyu and Holstein cattle to identify the metabolomic biomarkers characterizing the breed differences in beef taste.

\section{Results}

Gas chromatography-mass spectrometry (GC-MS) analysis detected 67 metabolites in the sirloin samples of Wagyu and Holstein. Full results are shown in Supplementary Table S1. The principal component analysis (PCA) score plots showed that the metabolomic profile was divided into Wagyu and Holstein groups (Figure 1). The heatmap of metabolites also showed a difference between Wagyu and Holstein groups (Figure 2). Metabolites contributing to cluster 7, which characterized the Holstein sample, were mainly composed of amino acids (proline and glycine), amino compounds (succinic acid, amino propanoic acid, creatinine, and pyruvic acid), and nucleic acid metabolites (inosine and ribose). In contrast, cluster 1 , which characterized the Wagyu sample, was mainly composed of sugar components (maltose and xylitol) and fatty acids (stearic acid, palmitic acid and nonanoic acid). Table 1 shows the differences in the relative quantity of the main metabolite compounds in Wagyu and Holstein samples. The amount of glutamine, ribose-5-phosphate, uric acid, inosine monophosphate, 5-oxoproline, and glycine in Holstein samples was significantly higher than in Wagyu samples. In contrast, the amount of maltose and xylitol in Wagyu samples was significantly higher than that in Holstein samples.

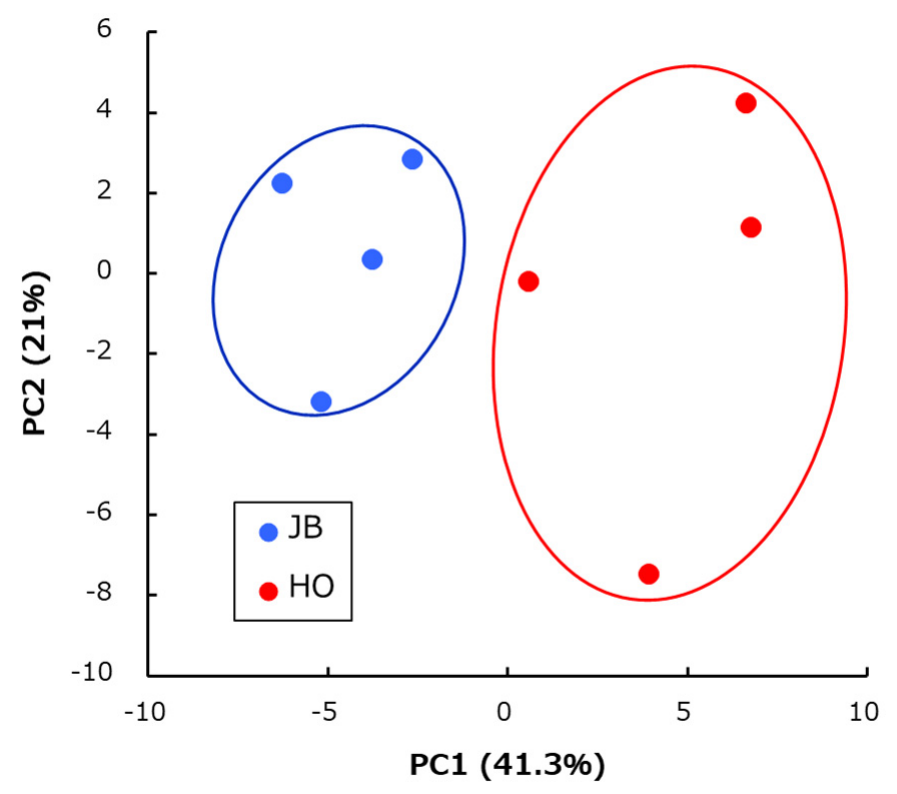

Figure 1. Principal component analysis (PCA) of metabolome data from Japanese Black Wagyu (JB) and Holstein $(\mathrm{HO})$ sirloin samples. $\bullet$ JB $(n=4), \bullet: \mathrm{HO}(n=4)$. 


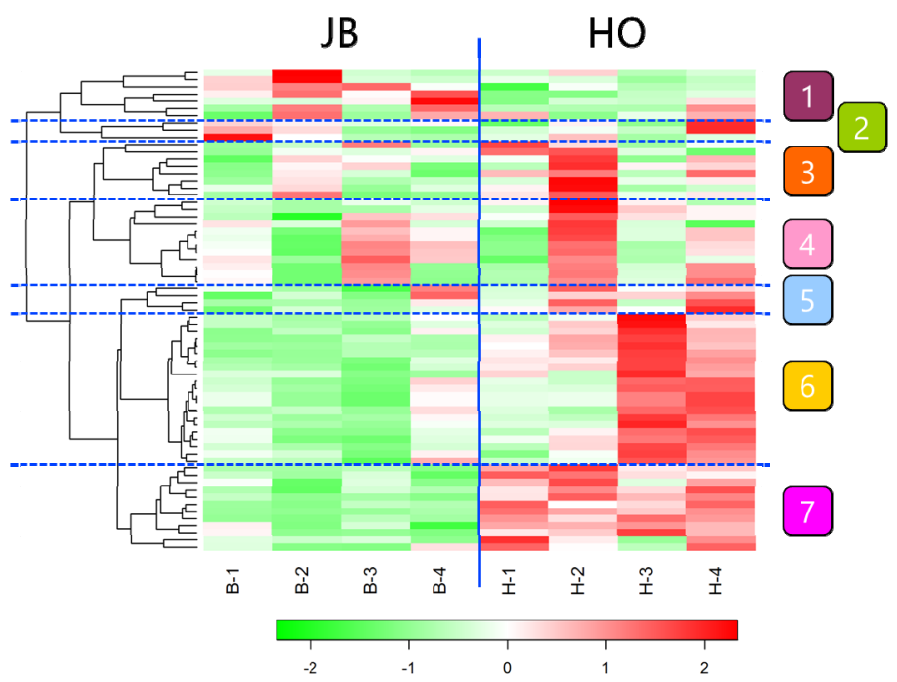

Figure 2. Heatmap of metabolites in Japanese Black Wagyu (JB) and Holstein (HO) sirloin samples. The upregulated metabolites are shown in red, and the downregulated metabolites are presented in green. Cluster 1, which characterized the Wagyu sample, was mainly composed of maltose, xylitol, stearic acid, palmitic acid, and nonanoic acid. Cluster 7, which characterized the Holstein sample, was mainly composed of proline, glycine, succinic acid, amino propanoic acid, creatinine, pyruvic acid, inosine, and ribose. B1-B4: Japanese Black Wagyu $(n=4)$; H1-H4: Holstein $(n=4)$.

Table 1. Main metabolite compounds in Japanese Black Wagyu and Holstein sirloin samples.

\begin{tabular}{|c|c|c|c|c|c|c|c|}
\hline \multirow{3}{*}{ Change } & \multirow{3}{*}{ Compound Name } & \multicolumn{4}{|c|}{ Relative Area } & \multirow{2}{*}{\multicolumn{2}{|c|}{$\frac{\text { Comparative Analysis }}{\text { JB/Ho }}$}} \\
\hline & & \multicolumn{2}{|c|}{ JB } & \multicolumn{2}{|c|}{ Ho } & & \\
\hline & & Mean & S.D. & Mean & S.D. & Ratio & $p$-Value \\
\hline \multirow[t]{8}{*}{ Increase } & Maltose & $7.1 \times 10^{4}$ & $1.4 \times 10^{4}$ & $4.0 \times 10^{4}$ & $1.5 \times 10^{4}$ & 1.8 & $0.022 *$ \\
\hline & Xylitol & $2.7 \times 10^{4}$ & $4.4 \times 10^{3}$ & $1.8 \times 10^{4}$ & $2.3 \times 10^{3}$ & 1.5 & $0.022 *$ \\
\hline & Palmitic acid & $8.8 \times 10^{4}$ & $3.6 \times 10^{4}$ & $6.0 \times 10^{4}$ & $8.8 \times 10^{3}$ & 1.5 & 0.221 \\
\hline & Stearic acid & $6.7 \times 10^{4}$ & $4.0 \times 10^{4}$ & $5.2 \times 10^{4}$ & $1.3 \times 10^{4}$ & 1.3 & 0.513 \\
\hline & Ribose & $4.3 \times 10^{5}$ & $1.2 \times 10^{5}$ & $3.5 \times 10^{5}$ & $5.6 \times 10^{4}$ & 1.2 & 0.264 \\
\hline & Sedoheptulose7-phosphate & $7.9 \times 10^{4}$ & $3.2 \times 10^{4}$ & $6.5 \times 10^{4}$ & $2.3 \times 10^{4}$ & 1.2 & 0.513 \\
\hline & Mannose & $1.1 \times 10^{6}$ & $2.7 \times 10^{5}$ & $8.9 \times 10^{5}$ & $2.8 \times 10^{5}$ & 1.2 & 0.406 \\
\hline & Glycerol 3-phosphate & $2.4 \times 10^{4}$ & $7.9 \times 10^{3}$ & $2.1 \times 10^{4}$ & $3.3 \times 10^{3}$ & 1.1 & 0.623 \\
\hline \multirow[t]{8}{*}{ Decrease } & Glycine & $1.6 \times 10^{6}$ & $1.1 \times 10^{5}$ & $2.6 \times 10^{6}$ & $2.4 \times 10^{5}$ & 0.6 & $0.001 * *$ \\
\hline & Ornithine & $3.9 \times 10^{4}$ & $6.3 \times 10^{3}$ & $6.7 \times 10^{4}$ & $2.3 \times 10^{4}$ & 0.6 & 0.094 \\
\hline & 5-Oxoproline & $9.2 \times 10^{4}$ & $9.2 \times 10^{3}$ & $1.7 \times 10^{5}$ & $3.2 \times 10^{4}$ & 0.6 & $0.014 *$ \\
\hline & Inosine monophosphate & $1.8 \times 10^{5}$ & $7.9 \times 10^{4}$ & $3.3 \times 10^{5}$ & $1.4 \times 10^{4}$ & 0.5 & $0.030 *$ \\
\hline & Uric acid & $1.1 \times 10^{4}$ & $1.4 \times 10^{3}$ & $2.2 \times 10^{4}$ & $4.8 \times 10^{3}$ & 0.5 & 0.014 * \\
\hline & 2-Hydroxyglutaric acid & $5.8 \times 10^{3}$ & $2.0 \times 10^{3}$ & $1.3 \times 10^{4}$ & $5.3 \times 10^{3}$ & 0.5 & 0.075 \\
\hline & Ribose 5-phosphate & $3.2 \times 10^{4}$ & $5.4 \times 10^{3}$ & $6.9 \times 10^{4}$ & $1.2 \times 10^{4}$ & 0.5 & $0.004^{* *}$ \\
\hline & Glutamine & $3.5 \times 10^{4}$ & $3.8 \times 10^{3}$ & $9.8 \times 10^{4}$ & $3.1 \times 10^{4}$ & 0.4 & $0.026^{*}$ \\
\hline
\end{tabular}

Values are expressed as means and S.D. ratio: fold intensity of metabolite compounds (JB/Ho). Annotation and relative quantification of metabolites was measured by each peak using the gas chromatography-mass spectrometry (GC-MS) solution (Shimadzu) and GC/MS Metabolite Database Ver. 2 (Shimadzu). Japanese Black Wagyu (JB, $n=4)$, Holstein $(\mathrm{HO}, n=4) * p<0.05, * * p<0.01$.

\section{Discussion}

In the present study, we showed that the Holstein sirloin samples were characterized by amino acids, amino compounds and nucleic-acid metabolites. We also showed that the relative amount of glutamine, ribose-5-phosphate, uric acid, inosine monophosphate, 5-oxoproline, and glycine in the Holstein sirloin samples was significantly higher than in the Wagyu samples. The abundance of amino acids, amino compounds, and nucleic-acid metabolites clearly reflects the lean meat content of Holstein beef. Previous studies also showed the relationship between metabolomic profiling and beef quality [7-11]. These results indicate that metabolomic analysis is an optimum approach to identify quality-related chemical components of beef. The cooking of meat forms a characteristic taste via 
numerous chemical reactions. The Maillard reaction is one of the major chemical reactions of cooked meat that produces many flavoring components [22]. Amino acids and nucleic-acid metabolites are main meat-flavor precursors for the Maillard reaction [23]. Therefore, a higher amount of amino acid and nucleic-acid metabolites in Holstein beef indicates the abundance of a Maillard reaction substrate. These results suggest that breed differences in beef metabolomic profiles affect the taste of cooked meats. The elucidation of metabolomic profile differences between Wagyu and Holstein cooked meat is an important subject for further study.

We showed that the Wagyu sirloin samples were characterized by sugar components and fatty acids. The present study also showed that the relative amount of maltose and xylitol in Wagyu sirloin samples was significantly higher than that in Holstein samples. Ueda et al. reported that the relative amount of malic acid, maltose, trehalose, arabitol, isomaltose, n-acetylserine, and inositol in Wagyu beef was significantly higher than that in Holstein beef [9]. The aging periods of beef affect the meat quality and metabolomic profile [11]. The difference between the results of our study and those of Ueda et al. would be attributed to meat aging conditions. The meat aging period in the present study was at $4{ }^{\circ} \mathrm{C}$ for 7 days after slaughter. In contrast, the aging in Ueda et al. was at $4{ }^{\circ} \mathrm{C}$ for 20 days [9]. On the other hand, results showing a higher amount of maltose in Wagyu beef than in Holstein beef were common to both experiments. These results suggest that a higher maltose concentration is a primary feature of Wagyu beef, independent of the aging period. The causative substance of the sweet taste of Wagyu beef remains unclear. Amino acids have different taste properties depending upon their chemical structure [24]. Glycine is categorized as a "sweet" amino acid [24]. The present results showed that glycine was abundant in the Holstein sirloin samples. Therefore, the possibility that amino acids contribute to the sweet taste of Wagyu beef would be excluded. In contrast, the present study showed that maltose and xylitol, categorized as sugar components, are abundant in Wagyu beef. Wagyu is characterized by higher intramuscular fat content than Holstein [12,13]. Previous reports indicated that dietary fat increased the intensity of sweet taste $[25,26]$. These results suggest that the sweet taste of Wagyu beef is affected by the synergetic interaction between higher sugar components and intramuscular fat. Threshold sweetness concentrations of maltose and xylitol have been reported using sensory test methods $[27,28]$. Kearsley et al. reported that the threshold sweetness concentration of maltose was $1.07 \%(\mathrm{w} / \mathrm{v})$, and that of xylitol was $0.51 \%(\mathrm{w} / \mathrm{v})$ [27]. In molar volumes, Birch et al. showed that the threshold sweetness concentration of maltose was $21.0 \mathrm{mM} / 1$, and that of xylitol was also $21.0 \mathrm{mM} / 1$ [28]. However, the effect of dietary fat on the threshold sweetness concentration of sugar components has not been reported. The slaughter age of Wagyu (aged 29-30 months) and Holsteins (aged 21-22 months) in this study was defined in accordance with the commonly applied fattening periods of each breed in Japan. Ueda et al. also analyzed beef samples of Wagyu (aged 31-32 months) and Holsteins (aged 21 months) that were similar to the age of cattle used in this study [9]. Previous studies have shown that the slaughter age affects meat quality and sensory traits of beef [29,30]. To our knowledge, there are no previous studies examining the effects of slaughter age on metabolomic profiling of beef. Therefore, the differences between fattening periods of Wagyu and Holsteins in this study may affect the metabolomic profiling of beef. In addition, there is a possibility that other metabolites, which we could not detect in this study, might affect the sweetness of beef. Further studies are needed to clarify the effects of metabolites on the sweet taste of Wagyu beef.

\section{Materials and Methods}

\subsection{Animals}

Wagyu steers (aged 29-30 months, $n=4$ ) and Holstein steers (aged 21-22 months, $n=4$ ) were used in this study. They received a concentrate (78\% total digestible nutrients and $13 \%$ crude protein) and orchard grass hay (56\% total digestible nutrients and 8\% crude protein) ad libitum from 10 months of age until they were slaughtered. Longissimus muscle (sirloin) samples were collected at slaughter. The sirloin samples $(1.5 \mathrm{~kg}$ ) were collected between the third and fourth lumbar vertebrae from the left 
side of the carcass. Samples were vacuum-packed and wet-aged at $4{ }^{\circ} \mathrm{C}$ for 7 days and then stored at $-80^{\circ} \mathrm{C}$ for later metabolome analysis. All animals received humane care as outlined in the Guide for the Care and Use of Experimental Animals (No.1631B004, National Agriculture and Food Research Organization).

\subsection{GC-MS Analysis}

Frozen sirloin samples were powdered with liquid nitrogen and weighed (100 $\mathrm{mg})$ in the frozen state. Frozen samples were plunged into $80 \%$ methanol and homogenized using zirconia beads and an ultrasonic homogenizer for $5 \mathrm{~min}$. The samples were centrifuged at 15,000 rpm for $5 \mathrm{~min}$. The supernatant was filtered using a Mono-Spin C18 column (GL Science, Tokyo, Japan), and then the filtration $(50 \mu \mathrm{L})$ was dried by a nitrogen gas flow. Methoxyamine hydrochloride solubilized with pyridine $(20 \mathrm{mg} / \mathrm{mL}, 50 \mu \mathrm{L})$ was added to each sample, and oxime formation was achieved by reacting at $30^{\circ} \mathrm{C}$ for $90 \mathrm{~min}$. Trimethylsilyl-trifluoroacetamide $(50 \mu \mathrm{L})$ was then added to each sample, and trimethylsilylation was carried out by reacting at $37^{\circ} \mathrm{C}$ for $30 \mathrm{~min}$. Analyses were performed on a gas chromatography-mass spectrometer (GC-MS, QP2010Ultra, Shimadzu, Kyoto, Japan) using a DB-5 column (Agilent Technologies, Santa Clara, CA, USA) at the Kazusa DNA Research Institute. The carrier gas was helium in a flow of $1.1 \mathrm{~mL} / \mathrm{min}$. The injection temperature was $280{ }^{\circ} \mathrm{C}$, and the injection volume was $0.5 \mu \mathrm{L}$. The temperature program was isothermal for $4 \mathrm{~min}$ at $100{ }^{\circ} \mathrm{C}$, then raised at a rate of $4{ }^{\circ} \mathrm{C} / \mathrm{min}$ to $320^{\circ} \mathrm{C}$ and held for $8 \mathrm{~min}$. The ion source temperature and scan speed were set to $200{ }^{\circ} \mathrm{C}$ and $2500 \mathrm{u} / \mathrm{sec}$, respectively. Sample peaks were recorded over the mass range of $45-600 \mathrm{~m} / \mathrm{z}$. The retention time correction of peaks was carried out based on the retention time of a standard alkane series mixture (C-7 to C-33). Annotation and relative quantification of metabolite was measured by each peak using the GC-MS solution (Shimadzu) and GC/MS Metabolite Database Ver. 2 (Shimadzu). The relative area was calculated using the peak area of each metabolite relative to the analyzed sample weight at Kazusa DNA Research Institute.

\subsection{Statistical Analysis}

Principal component analysis (PCA) was conducted using SampleStat software (Human Metabolome Technologies, Japan). Hierarchical cluster analysis (HCA) was performed and heatmap formation analyzed using PeakStat software (Human Metabolome Technologies). Differences between the relative quantity of metabolites in Wagyu and Holstein samples were evaluated using Welch's t-test. Results are presented as means, and S.D. values of $p<0.05$ were considered significant.

Supplementary Materials: The following are available online at http://www.mdpi.com/2218-1989/10/3/95/s1, Table S1: Metabolites of Wagyu and Holstein Beef.

Author Contributions: Conceptualization, T.Y. and M.H.; methodology, T.Y.; software, T.Y.; validation, T.Y., M.K., and M.H.; formal analysis, T.Y.; investigation, T.Y., M.K., and M.H.; resources, T.Y., M.K., and M.H.; data curation, T.Y., M.K., and M.H.; writing—original draft preparation, T.Y.; writing—review and editing, T.Y., M.K., and M.H.; visualization, T.Y.; supervision, T.Y.; project administration, T.Y.; funding acquisition, T.Y. All authors have read and agreed to the published version of the manuscript.

Funding: This work was supported in part by a Grant-in-Aid for Ito Memorial Foundation and JSPS KAKENHI (18K05958).

Acknowledgments: We would like to thank Kazuki Iguchi (Human Metabolome Technologies) for technical support.

Conflicts of Interest: The authors declare no conflict of interest.

\section{References}

1. Takahashi, K.; Kohno, H. Different polor metabolites and protein profiles between high- and low-quality Japanese Ginjo sake. PLoS ONE 2016, 11, e0150524. [CrossRef] [PubMed]

2. Sugimoto, M.; Goto, H.; Otomo, K.; Ito, M.; Onuma, H.; Suzuki, A.; Sugawara, M.; Abe, S.; Tomita, M.; Soga, T. Metabolomic profiles and sensory attributes of edamame under various storage duration and temperature conditions. J. Agric. Food Chem. 2010, 58, 8418-8425. [CrossRef] [PubMed] 
3. Malmendal, A.; Amoresano, C.; Trotta, R.; Lauri, I.; De Tito, S.; Novellino, E.; Randazzo, A. NMR spectrometers as "magic tongues": Prediction of sensory descriptors in canned Tomatos. J. Agric. Food Chem. 2011, 59, 10831-10838. [CrossRef] [PubMed]

4. Sugimoto, M.; Obiya, S.; Kaneko, M.; Enomoto, A.; Honma, M.; Wakayama, M.; Soga, T.; Tomita, M. Metabolic profiling as a possible reverse engineering tool for estimating processing conditions of dry-cured hams. J. Agric. Food Chem. 2017, 65, 402-410. [CrossRef] [PubMed]

5. Muroya, S.; Oe, M.; Nakajima, I.; Ojima, K.; Chikuni, K. CE-TOFMS-based metabolomic profiling revealed characteristic metabolic pathways in postmortem porcine fast and slow type muscles. Meat Sci. 2014, 98, 726-735. [CrossRef] [PubMed]

6. Straadt, I.K.; Aaslyng, M.D.; Bertram, H.C. An NMR-based metabolomics study of pork from different crossbreeds and relation to sensory perception. Meat Sci. 2014, 96, 719-728. [CrossRef] [PubMed]

7. Jung, Y.; Lee, J.; Kwon, J.; Lee, K.S.; Ryu, D.H.; Hwang, G.S. Discrimination of the geographical origin of beef by H NMR-based metabolomics. J. Agric. Food Chem. 2010, 58, 10458-10466. [CrossRef]

8. Ritota, M.; Casciani, L.; Failla, S.; Valentin, M. HRMAS-NMR spectroscopy and multivariate analysis meat characterization. Meat Sci. 2012, 92, 754-761. [CrossRef]

9. Ueda, S.; Iwamoto, E.; Kato, Y.; Shinohara, M.; Shirai, Y.; Yamanoue, M. Comparative metabolomics of Japanese Black cattle beef and other meats using gas chromatography-mass spectrometry. Biosci. Biotechnol. Biochem. 2019, 83, 137-147. [CrossRef]

10. Argyri, A.A.; Mallouchos, A.; Panagou, E.Z.; Nychas, G.J.E. The dynamics of the HS/SPME-GC-MS as a tool to assess the spoilage of minced beef stored under different packaging and temperature conditions. Int. J. Food Microbiol. 2015, 193, 51-58. [CrossRef]

11. Muroya, S.; Oe, M.; Ojima, K.; Watanabe, A. Metabolomic approach to key metabolites characterizing postmortem aged loin muscle of Japanese Black (Wagyu) cattle. Asian-Australas. J. Anim. Sci. 2019, 32, 1172-1185. [CrossRef] [PubMed]

12. Zembayashi, M.; Lunt, D.K. Distribution of intramuscular lipid throughout M. longissimus thoracis et lumborum in Japanese Black, Japanese Shorthorn, Holstein and Japanese Black crossbreds. Meat Sci. 1995, 211-216. [CrossRef]

13. Motoyama, M.; Sasaki, K.; Watanabe, A. Wagyu and the factors contributing to its beef quality: A Japanese industry overview. Meat Sci. 2016, 120, 10-18. [CrossRef] [PubMed]

14. Corbin, C.H.; O'Quinn, T.G.; Garmyn, A.J.; Legato, J.F.; Hunt, M.R.; Dinh, T.T.N.; Rathmann, R.J.; Brooks, J.C.; Miller, M.F. Sensory evaluation of tender beef strip loin steaks of varying marbling levels and quality treatments. Meat Sci. 2015, 100, 24-31. [CrossRef] [PubMed]

15. Sasaki, K.; Ooi, M.; Nagura, N.; Motoyama, M.; Narita, T.; Oe, M.; Nakajima, I.; Tatsuro, H.; Ojima, K.; Kobayashi, M.; et al. Classification and characterization of Japanese consumer's beef preferences by external preference mapping. J. Sci. Food. Agric. 2017, 97, 3453-3462. [CrossRef]

16. Watanabe, G.; Motoyama, M.; Orita, K.; Takita, K.; Aonuma, T.; Nakajima, I.; Tajima, A.; Abe, A.; Sasaki, K. Assessment of the dynamics of sensory perception of Wagyu beef strip loin prepared with different cooking methods and fattening periods using the temporal dominance of sensations. Food Sci. Nutr. 2019, 7, 3538-3548. [CrossRef]

17. Matsuishi, M.; Fujimori, M.; Okitani, A. Wagyu beef aroma in Wagyu (Japanese Black Cattle) beef preferred by the Japanese over imported beef. Anim. Sci. J. 2001, 72, 498-504. [CrossRef]

18. Matsuishi, M.; Kume, J.; Itou, Y.; Takahashi, M.; Arai, M.; Nagatomi, H.; Watanabe, K.; Hayase, F.; Okitani, A. Aroma components of Wagyu beef and imported beef. Nihon Chikusan Gakkaiho 2004, 75, 409-415. [CrossRef]

19. Inagaki, S.; Amano, Y.; Kumazawa, K. Identification and characterization of volatile components causing the characteristics flavor of Wagyu beef (Japanese Black cattle). J. Agric. Food. Chem. 2017, 65, 8691-8695. [CrossRef]

20. Matsuzaki, M.; Takizawa, S.; Ogawa, M. Plasma insulin metabolite concentrations and carcass characteristics of Japanese Black, Japanese Brown, and Holstein steers. J. Anim. Sci. 1997, 75, 3287-3293. [CrossRef]

21. Yamada, T.; Kawakami, S.; Nakanishi, N. Expression of adipogenic transcription factors in adipose tissue of fattening Wagyu and Holstein steers. Meat Sci. 2009, 81, 86-92. [CrossRef] [PubMed]

22. Kerth, C.R.; Miller, R.K. Beef flavor: A review from chemistry to consumer. J. Sci. Food Agric. 2015, 95, 2783-2798. [CrossRef] [PubMed] 
23. Khan, M.I.; Jo, C.; Tariq, M.R. Meat flavor precursors and factors influencing flavor precursors-A systematic review. Meat Sci. 2015, 110, 278-284. [CrossRef] [PubMed]

24. Kawai, M.; Sekine-Hayakawa, Y.; Okiyama, A.; Ninomiya, Y. Gustatory sensation of L- and D- amino acids in humans. Amino Acids. 2012, 43, 2349-2358. [CrossRef] [PubMed]

25. Tuoria, H.; Sommardahl, C.; Hyvönen, L.; Leporanta, K.; Merimma, P. Does fat affect the timing of flavor perception? a case study with yoghurt. Food Qual. Pref. 1995, 6, 55-58. [CrossRef]

26. Metcalf, K.L.; Vickers, Z.M. Taste intensities of oil-in-water emulsions with varying fat content. J. Sens. Stud. 2002, 17, 379-390. [CrossRef]

27. Kearsley, M.W.; Dziedzic, S.Z.; Birch, G.G.; Smith, P.D. The production and properties of glucose syrups III. Sweetness of glucose syrups and related carbohydrates. Starch 1980, 32, 244-247. [CrossRef]

28. Birch, G.G.; Munton, S.L. Evidence for constant number of available sweet receptor sites at threshold concentration of sugars. Experientia 1981, 37, 839-840. [CrossRef]

29. Bouton, P.E.; Ford, P.V.; Harris, P.V.; Shorthose, W.R.; Ratcliff, D.; Morgan, J.H.L. Influence of animal age on the tenderness of beef: Muscle differences. Meat Sci. 1978, 2, 301-311. [CrossRef]

30. Okumura, T.; Saito, K.; Sowa, T.; Sakuma, H.; Ohhashi, F.; Tameoka, N.; Hirayama, M.; Nakayama, S.; Sato, S.; Gogami, T.; et al. Changes in beef sensory traits as somatic-cell-cloned Japanese black steers increased in age from 20 to 30 months. Meat Sci. 2012, 90, 159-163. [CrossRef]

(C) 2020 by the authors. Licensee MDPI, Basel, Switzerland. This article is an open access article distributed under the terms and conditions of the Creative Commons Attribution (CC BY) license (http://creativecommons.org/licenses/by/4.0/). 